\title{
Gender differences in health care utilization and outcome of respiratory tuberculosis in Alexandria
}

M.I. Kamel, ${ }^{1}$ S. Rashed, ${ }^{1}$ N. Foda,${ }^{1}$ A. Mohie ${ }^{1}$ and M. Loutfy ${ }^{2}$

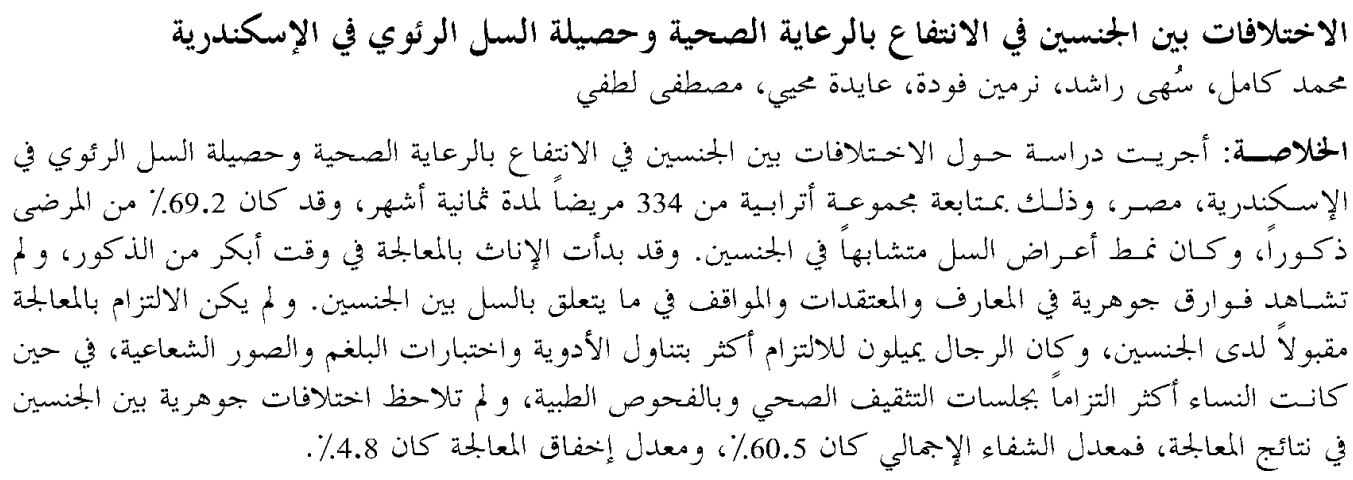

ABSTRACT A study of gender differences in health care utilization and outcome of respiratory tuberculosis was carried out in Alexandria, Egypt. A cohort of 334 patients was followed-up for 8 months; $69.2 \%$ of cases were males. The pattern of tuberculosis symptoms was similar for both sexes. Women started treatment earlier than men. Women had significantly lower scores in knowledge, beliefs and attitudes about tuberculosis than men. Compliance was unsatisfactory for both sexes. Men tended to be more adherent to drugs and to sputum and X-ray examinations but there were no sex differences in compliance with health education and medical examinations. No significant sex differences in treatment outcome were found: the overall cure rate was $60.5 \%$ and treatment failure was $4.8 \%$. Multiple regression analysis showed satisfaction with medical care was the only significant predictor of treatment failure.

\begin{abstract}
Différences selon les sexes dans l'utilisation des soins de santé et l'évolution de la tuberculose respiratoire à Alexandrie

RESUME Une étude sur les différences selon les sexes dans l'utilisation des soins de santé et l'évolution de la tuberculose respiratoire a été réalisée à Alexandrie (Egypte). Une cohorte de 334 patients a été suivie pendant 8 mois ; 69,2\% des cas étaient des hommes. La physionomie des symptômes de la tuberculose était identique pour les deux sexes. Les femmes débutaient le traitement plus tôt que les hommes. II n'y avait aucune différence significative entre les hommes et les femmes dans les connaissances, croyances et attitudes à l'égard de la tuberculose. L'observance était peu satisfaisante pour les deux sexes. Les hommes avaient tendance à se conformer davantage aux prescriptions médicamenteuses et aux examens radiographiques et bactériologiques tandis que les femmes avaient une meilleure observance en ce qui concerne l'éducation sanitaire et les examens médicaux. Aucune différence significative entre les sexes n'a été observée dans les résultats du traitement : le taux de guérison global était de 60,5\% et l'échec du traitement de $4,8 \%$. Une analyse de régression multiple a révélé que la satisfaction quant aux soins médicaux constituait l'unique facteur prédictif important de l'échec du traitement.
\end{abstract}

${ }^{1}$ Department of Community Medicine, Faculty of Medicine, University of Alexandria, Alexandria, Egypt. ${ }^{2}$ Tuberculosis Control Programme, Directorate of Health Affairs, Alexandria Ministry of Health, Alexandria, Egypt.

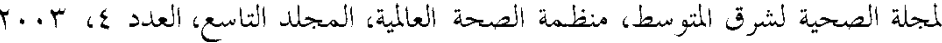




\section{Introduction}

Despite the efforts of the Egyptian National Tuberculosis Programme, tuberculosis (TB) remains a major public health problem in Egypt. Although the directly observed treatment, short course (DOTS) strategy has led to a substantial reduction in the prevalence of $\mathrm{TB}$, the national and global cure rate target of $85 \%$ has not yet been achieved (the cure rate was $77 \%$ in 1999) [1]. National TB programmes in most governorates have reported an excess of male over female TB cases each year. In Alexandria, the male to female ratio of registered TB cases varied between 2.6:1 (in 1997) to 1.7:1 (in 2001). In addition, women were more likely to have poorer treatment outcomes and higher case fatality compared with men. There is evidence that women confront more barriers than men in accessing TB care services [2], but the reasons for this difference are unclear.

There has been little research and discussion of gender and TB in the literature $[3,4]$. Worldwide, more men than women are diagnosed with TB. The TB programmes in many parts of the world register up to three times more men than women for treatment. There are indications that more women progress from infection to disease and there is a higher case fatality for women in their early reproductive ages. It is not clear to what extent these differences result from biological factors or geographical or sociocultural differences, such as under-recognition of TB among women $[5,6]$.

Gender analysis in health goes beyond questions of biological differences by attempting to understand the different experiences of women and men in economic, social and psychological terms, such as differences in ability to access services, experiences of health care, attitudes to health and disease (e.g. stimatization), so- cial structures (e.g. women's role as carers in the home), and aspects of economic and social status [7-9].

The objectives of the present study were:

- to determine the sex ratio among registered pulmonary TB cases;

- to describe and compare the utilization patterns of TB services and between male and female TB patients;

- to describe and compare outcomes of TB treatment between male and female TB patients;

- to identify factors behind gender differences in health seeking behaviour, diagnostic delay, TB treatment adherence (compliance behaviour) and subsequent treatment outcomes.

\section{Methods}

\section{Data collection}

Both descriptive and analytical epidemiological approaches were adopted. A crosssectional comparative study design was used to describe and compare the distribution of a number of variables in male and female TB cases, and to explore the existence of a possible causal association between sex and treatment adherence and outcomes. Having established the factors that were associated with gender differences, a cohort study was used to measure the extent to which these factors cause or contribute to the problem (i.e. to measure the strength of association and to quantify risk).

The main study sample was all 260 newly diagnosed pulmonary TB cases who commenced anti-TB therapy through the DOTS programme during December 2001 to November 2002. All were registered at the 7 chest clinics in Alexandria (ElMaamoura, Bacous, Moharrem Bey, El-

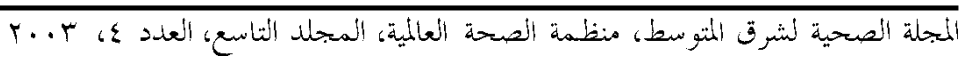


Gomrok, El-Kabbary, Karmouz and El-Amria). Patients were followed-up for 8 months. Their records and treatment control cards were reviewed monthly and treatment compliance was noted. Another group of 74 patients who had started treatment within the 3 months preceding the study were also included. Their compliance with treatment before the study was assessed by reviewing their records retrospectively. Afterwards, they were followed-up prospectively in the same way.

A structured interview questionnaire was used to collect the following data: demographic and socioeconomic background; patient's satisfaction with the quality of care provided; and patient's knowledge, attitudes, beliefs and opinions about TB. The interview also collected more details about data obtained from records and treatment control cards: clinical, microbiological, radiological and treatment data; patient's adherence to treatment; treatment response; and TB outcome classification at completion of therapy. Patients were interviewed at the chest clinic; newly diagnosed cases were interviewed at least 1 month after their diagnosis and starting treatment. Those who did not attend during the period of the study were interviewed at home.

Seven trained nurses and physicians were selected from the chest clinics to collect data from the records as well as interview patients in the clinics and collect the required information. Two field supervisors regularly monitored the process of data collection for adequacy and quality. A sample of 35 patients were interviewed as a pilot to assess the study tools, estimate the time required for filling the questionnaire and collecting data from the records and to assess the performance of data collectors and quality of training.

All the TB-related definitions (new case, relapse, treatment failure, cure, treatment completed and default) used in this study were the WHO-recommended definitions stipulated by the policy of the Egyptian National Tuberculosis Programme [1].

\section{Data analysis}

Mean percentage scores were calculated as follows: (score) $\times 100 /$ (maximum possible score), where score was the number of questions. The score of negative questions was first reversed before addition to its domain. Calculated domains were: perceptions about TB, satisfaction with services, communication, family relationships, and impact on reproductive health of women. Each question was rated on a 5-point scale.

The overall percentage compliance during the follow-up period was calculated out of the expected maximum. For drug compliance, the consumed units of treatment were calculated as a percentage of the assigned total units. Compliance with examinations, attending health education sessions, sputum examinations and chest $\mathrm{X}$-rays was defined as performing $80 \%$ or more of the required visits. Drug compliance at follow-up visits was defined as consumption of $80 \%$ or more of the assigned units.

Epi-Info, version 6.03 was used for tabulation and statistical analysis of the results. Data files were constructed before data entry and complete variable and value labelling were selected to facilitate interpretation of the computer output. The statistical methods used included descriptive measures (frequency, percentage, arithmetic mean, and standard deviation) and statistical tests (Student $t$-test, Mann-Whitney test, chi-squared test and multiple logistic regression analysis). The level of significance for the study was 0.05 .

\section{Ethical considerations}

After approval by WHO, the proposed research was approved by the Directorate of

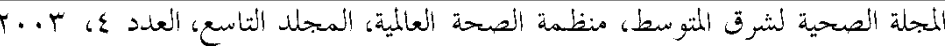


Health Affairs in Alexandria and the local TB control project managers. All participants gave their informed oral consent voluntarily.

\section{Results}

A total of 334 TB patients were registered at the 7 chest dispensaries in Alexandria during the study year.

\section{Characteristics of TB patients Personal data}

More of the TB cases were male than female (69.2\% compared with $30.8 \%$ ), with an overall male to female ratio of $2.2: 1$. The age of TB patients ranged from 14 to 75 years with a mean of $36.9 \pm 14.6$ years. The mean age of the men (36.5 \pm 13.4 years) was lower than the women (37.8 \pm 15.0 years) but not significantly so. Significantly more women than men were married $(61.2 \%$ versus $57.6 \%)$ or widowed $(10.7 \%$ versus only $0.4 \%)\left(\chi_{3}^{2}=25.073, P\right.$ $<0.001)$. Similar proportions of females and males (2.9\% versus $2.6 \%$ ) were divorced. More male TB patients than females were born in Alexandria governorate $(84.0 \%$ versus $73.8 \%)\left(\chi_{1}^{2}=4.78, P=\right.$ 0.029).

\section{Social characteristics}

A significant sex difference was observed in educational level $\left(\chi_{5}^{2}=16.432, P=\right.$ $0.012)$. More women than men were illiterate $(46.6 \%$ versus $39.0 \%)$, or had obtained a primary certificate (15.5\% versus $9.1 \%)$ or university one (8.8\% versus $3.9 \%)$. The majority of female patients were not working $(93.2 \%)$, whereas only $24.6 \%$ of male patients were unemployed $\left(\chi_{6}^{2}=137.613, P\right.$ $<0.001)$. The majority of men $(69.7 \%)$ were the sole breadwinners compared with less than a fifth of women (18.4\%). The husband was considered as family head for the majority of women $(80.6 \%)$; the father was rarely the family head for either male or female patients $(0.4 \%$ and $1.0 \%)\left(\chi_{2}^{2}=\right.$ 76.855, $P<0.001)$.

The men were more likely than the women to be current smokers (24.2\% versus $3.9 \%)$ or ex-smokers (57.1\% versus $1.9 \%)\left(\chi_{2}^{2}=167.572, P<0.001\right)$. A total of $11.3 \%$ of males and $1.9 \%$ of females admitted to a having a drug addiction to cannabis or heroin $\left(\chi_{1}^{2}=8.046, P=0.005\right)$.

\section{Housing environment}

The mean family size of TB patients was $4.24 \pm 1.84$ persons (range $1-11$ ), significantly higher for female $(4.54 \pm 1.73)$ than male patients (4.05 \pm 1.97$)$ (Mann-Whitney $Z=2.674, P=0.008)$. The crowding index of the sample ranged from $0.2-7$ persons per room with a mean of $1.65 \pm 1.06$. The mean crowding index for women $(1.77 \pm$ 1.05) was significantly higher than for men $(1.60 \pm 1.07)(Z=1.985, P=0.005)$.

\section{Clinical features of TB}

Table 1 shows the pattern of the disease at the time of interview, namely type, diagnosis, treatment regimen, duration and manifestations of TB. Similar proportions of men and women were diagnosed with pulmonary TB (97.8\% and $97.1 \%$ respectively). More than three-quarters (77.8\%) of TB patients were new cases who had taken anti-TB chemotherapy for less than 1 month. Relapsed cases (declared cured in the past by the physician) constituted $13.5 \%$ overall, with a predominance of females (16.5\%). Patients being treated after previous defaulting and treatment failure were $6.3 \%$ and a few patients $(2.4 \%)$ were completing their treatment. A statistical significant difference was observed between the sexes in the diagnosis at interview $(P=$ 0.043). No statistical significant differences in the treatment regimen were observed between the sexes $(P=0.274)$.

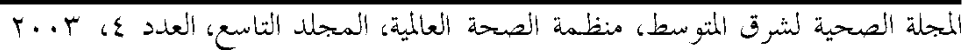


No statistically significant difference was observed in the mean duration of the disease for males ( $4.4 \pm 6.2$ months) and females (5.1 \pm 4.7 months) $(P=0.113)$.

Weight loss, dyspnoea, chest pain and fever were the main clinical manifestations among TB patients. Less common symptoms were urticaria, purpura, jaundice and urinary incontinence; only purpura showed a statistically significant difference $(P=$ 0.0003 ) between the sexes.

\section{Utilization of health care facilities}

A minority of both males (6.1\%) and females $(8.7 \%)$ received TB treatment in other health facilities in addition to treatment inside chest hospitals and clinics $(P=$ $0.167)$. The number of hospital admissions

\begin{tabular}{|c|c|c|c|c|c|c|c|c|}
\hline \multirow[t]{2}{*}{ Tuberculosis } & \multicolumn{2}{|c|}{ Males $(n=231)$} & \multicolumn{2}{|c|}{ Females $(n=103)$} & \multicolumn{2}{|c|}{ Total $(n=334)$} & \multirow[t]{2}{*}{ Test $^{a}$} & \multirow[t]{2}{*}{$P$-value } \\
\hline & No. & $\%$ & No. & $\%$ & & $\%$ & & \\
\hline \multicolumn{8}{|l|}{ Type of TB } & \multirow[t]{3}{*}{$0.706^{a}$} \\
\hline Pulmonary & 226 & 97.8 & 100 & 97.1 & 326 & 97.6 & & \\
\hline \multicolumn{7}{|l|}{ Pulmonary \& extra- } & & \\
\hline Diagnosis at interview & & & & & & & \multirow[t]{5}{*}{$\chi^{2}=11.74$} & \multirow[t]{5}{*}{0.043} \\
\hline New case & 187 & 81.0 & 73 & 70.9 & 260 & 77.8 & & \\
\hline Relapse & 28 & 12.1 & 17 & 16.5 & 45 & 13.5 & & \\
\hline Treatment after failure & 14 & 6.1 & 7 & 6.8 & 21 & 6.3 & & \\
\hline Treatment after default & 2 & 0.9 & 6 & 5.8 & 8 & 2.4 & & \\
\hline \multicolumn{9}{|l|}{ Treatment regimen ${ }^{b}$} \\
\hline I & 143 & 61.9 & 56 & 54.4 & 199 & 59.6 & \multirow[t]{3}{*}{$\chi^{2}=2.591$} & \multirow[t]{3}{*}{0.274} \\
\hline ॥ & 41 & 17.7 & 18 & 17.5 & 59 & 17.7 & & \\
\hline III & 47 & 20.4 & 29 & 28.1 & 7 & 22.7 & & \\
\hline \multicolumn{9}{|l|}{ Duration of disease } \\
\hline \multicolumn{9}{|l|}{ Clinical signs } \\
\hline Productive cough & 231 & 100.0 & 103 & 100.0 & & & & \\
\hline Weight loss & 192 & 83.1 & 86 & 83.5 & 278 & 83.2 & $\chi^{2}=0.007$ & 0.932 \\
\hline Dyspnoea & 164 & 71.0 & 74 & 71.8 & 238 & 71.3 & $\chi^{2}=0.025$ & 0.874 \\
\hline Chest pain & 102 & 44.2 & 47 & 45.6 & 149 & 44.6 & $\chi^{2}=0.063$ & 0.802 \\
\hline Fever & 75 & 32.5 & 36 & 35.0 & 111 & 33.2 & $\chi^{2}=0.198$ & 0.656 \\
\hline Urticaria & 17 & 7.4 & 6 & 5.8 & 23 & 6.9 & $\chi^{2}=0.261$ & 0.609 \\
\hline Jaundice & 10 & 4.3 & 2 & 1.9 & 12 & 3.6 & & $0.228^{c}$ \\
\hline Purpura & 6 & 2.6 & 15 & 14.6 & 21 & 6.3 & $\chi^{2}=17.31$ & 0.0003 \\
\hline Urinary incontinence & 4 & 1.7 & 5 & 4.9 & 9 & 2.7 & & $0.106^{c}$ \\
\hline $\begin{array}{l}\mathrm{n}=\text { total number of respon } \\
\mathrm{s}=\text { standard deviation. } \\
{ }^{a} \chi^{2}=\text { chi-squared test, } \mathrm{Z}=\Lambda \\
{ }^{b} \mathrm{WHO} \text { definitions. } \\
{ }^{c} \text { Fisher exact test. }\end{array}$ & $\begin{array}{l}\text { dents. } \\
\text { Mann Wr }\end{array}$ & itney test, & & & & & & \\
\hline
\end{tabular}

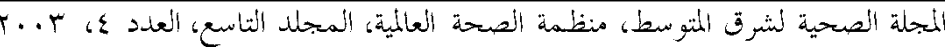


during the previous year ranged from 0 to 3 with a mean of $0.55 \pm 0.45$ times. More males were hospitalized once (38.1\%) than females (31.1\%); however, more females (5.8\%) than males (2.6\%) were hospitalized twice. The mean days of hospital admission was $54.9 \pm 53.6$ days overall (range 1-260), significantly higher for women (75.2 \pm 63.9 days) than men (45.6 \pm 46.3 days $)(P=0.003)$.

\section{Factors affecting pattern of utilization of the available services}

\section{Health seeking behaviour}

More women than men had attended a private clinic for the diagnosis of TB $(28.8 \%$ versus $14.7 \%$ ), whereas more men than women had visited a public chest clinic (51.5\% versus $42.7 \%$ ) or public chest hospital (32.5\% versus $20.4 \%)(P<0.001)$.

The first facilities that patients sought when they needed care also differed but not significantly $(P=0.167)$. More male patients than female patients preferred chest hospitals (30.7\% versus $25.2 \%$ ) and chest clinics (52.8\% versus $48.5 \%$ ). On the other hand, more women than men used general hospitals (3.9\% versus $1.3 \%$ ), private clinics (20.4\% versus $14.7 \%$ ) and other health facilities $(1.9 \%$ versus $0.4 \%$ respectively).

A significantly higher proportion of female patients (35.0\%) used traditional medicines for treatment of TB compared with males $(24.2 \%)(P=0.043)$.

Past adherence to treatment, follow-up and health education sessions

The majority of TB patients (85.0\%) said they had been adherent to treatment in the past; more females than males (86.4\% versus $84.4 \%$ ). A total of $15.0 \%$ of patients had stopped treatment, significantly more males than females $(P=0.0412)$. Just less than a tenth of females $(9.7 \%)$ had stopped treatment due to minor side-effects (which are not indications for stopping treatment) compared with $8.7 \%$ of males. However, more males (6.9\%) than females (3.9\%) had stopped treatment due to the time and money cost.

Home visits were made to $18.0 \%$ of TB patients; more women (19.4\%) than men (17.3\%) were visited but this was not statistically significant $(P=0.064)$. The majority of the TB patients (94.9\%) attended the clinic regularly. However, 5.1\% of them stopped attending, $5.8 \%$ of females and $4.9 \%$ of males $(P=0.683)$. The majority of TB patients $(92.5 \%)$ did not miss any health education sessions. However, a significantly higher percentage of women $(11.7 \%)$ missed one or more health education sessions compared with only $5.6 \%$ of men $(P=0.050)$.

\section{Sources of knowledge about TB}

The chest clinic was the main source of knowledge for the majority of both men (74.4\%) and women (69.0\%). Fewer patients $(11.6 \%$ of females and $10.4 \%$ of males) were informed about TB through the mass media. More females (11.6\%) than males (5.2\%) were informed about TB through other patients. Other sources of knowledge included private physicians and nurses $(10.0 \%$ of males and $7.8 \%$ of females $)(P=0.295)$.

\section{Diagnosis and treatment delay}

The time elapsed from the appearance of clinical signs of TB until seeking health care ranged from 0 to 4 months with a mean of $2.2 \pm 5.1$ months (Table 2). No statistical significant difference was observed between male and female patients in the delay before diagnosis. The delay in starting treatment, however, ranged from 1 to 21 weeks (mean $1.3 \pm 1.5$ weeks), and was significantly higher for males (1.4 \pm 1.7 weeks) than females $(1.2 \pm 1.3$ weeks $)$

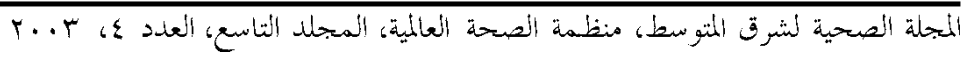


$(P<0.001)$. Table 2 shows that $64.4 \%$ of patients received treatment within the first week of diagnosing the disease.

Accessibility to health care facilities

Distance to the clinic for patients ranged from 0.1 to $60.0 \mathrm{~km}$ with a mean of $9.8 \pm$ $10.8 \mathrm{~km}$ and a median of $9.0 \mathrm{~km}$. Female patients lived on average $8.1 \pm 9.2 \mathrm{~km}$ away from the health service compared with $10.1 \pm 11.9 \mathrm{~km}$ for male patients $(P=$ 0.323). The mean commuting time to the chest clinic was $23.3 \pm 18.6$ min (range $1-$ 20), with no significant difference between males (22.4 $\pm 16.4 \mathrm{~min})$ and females (24.9 $\pm 22.3 \mathrm{~min})(P=0.868)$. About half the patients $(52.4 \%)$ were within walking distance $(<5 \mathrm{~km})$ of the chest clinics. Slightly more men (24.2\%) went to the clinic on foot compared with $19.4 \%$ of women. The latter tended to use public transport slightly more than males (16.5\% versus $13.9 \%)$. The most common means of transport (microbus) was equally utilized by both sexes (55.4\% and $55.3 \%$ respectively) ( $P=$ $0.568)$.

\section{Patient satisfaction with care and perceptions about TB}

Satisfaction with the quality of health care provided

Men tended to be more satisfied with the clinic working hours than women but not significantly so $(67.1 \%$ reported them 'very suitable' compared with 61.2\%) $(P=$ $0.257)$. Satisfaction with waiting time, waiting places, communication with staff, availability of investigations, health education sessions, social services and follow-up at home did not differ significantly between the sexes. The overall mean satisfaction

\begin{tabular}{|c|c|c|c|c|c|c|c|c|}
\hline \multirow[t]{2}{*}{ Characteristics } & \multicolumn{2}{|c|}{$\begin{array}{c}\text { Males } \\
(n=231)\end{array}$} & \multicolumn{2}{|c|}{$\begin{array}{l}\text { Females } \\
(n=103)\end{array}$} & \multicolumn{2}{|c|}{$\begin{array}{c}\text { Total } \\
(n=103)\end{array}$} & \multirow{2}{*}{$\begin{array}{c}\text { Mann- } \\
\text { Whitney } \\
z\end{array}$} & \multirow[t]{2}{*}{$P$-value } \\
\hline & No. & $\%$ & No. & $\%$ & No. & $\%$ & & \\
\hline \multicolumn{9}{|l|}{$\begin{array}{l}\text { Diagnostic delay } \\
\text { (months) }\end{array}$} \\
\hline$<1$ & 75 & 32.5 & 35 & 34.0 & 110 & 32.9 & & \\
\hline $1-$ & 76 & 32.9 & 27 & 26.2 & 103 & 30.8 & & \\
\hline $2-$ & 61 & 26.4 & 29 & 28.2 & 90 & 27.0 & & \\
\hline $4+$ & 19 & 8.2 & 12 & 11.7 & 31 & 9.3 & & \\
\hline Mean $\pm s$ & \multicolumn{2}{|c|}{$2.2 \pm 7.9$} & \multicolumn{2}{|c|}{$2.1 \pm 3.0$} & \multicolumn{2}{|c|}{$2.2 \pm 5.1$} & 0.902 & 0.367 \\
\hline \multicolumn{9}{|l|}{$\begin{array}{l}\text { Treatment delay } \\
\text { (weeks) }\end{array}$} \\
\hline$<1$ & 162 & 70.1 & 53 & 51.5 & 215 & 64.4 & & \\
\hline $1-$ & 25 & 10.8 & 8 & 7.8 & 33 & 9.9 & & \\
\hline $2-$ & 12 & 5.2 & 12 & 11.7 & 24 & 7.2 & & \\
\hline $4+$ & 32 & 13.9 & 30 & 29.1 & 62 & 18.6 & & \\
\hline Mean $\pm s$ & \multicolumn{2}{|c|}{$1.4 \pm 1.7$} & \multicolumn{2}{|c|}{$1.2 \pm 1.3$} & \multicolumn{2}{|c|}{$1.3 \pm 1.5$} & 3.934 & 0.0001 \\
\hline
\end{tabular}

المجلة الصحية لشرق المتوسط، منظمة الصحة العالمية، المجلد التاسع، العلد ع، بr... 
score $(82.5 \% \pm 13.5 \%)$ was very similar for both males and females $(82.8 \% \pm$ $12.8 \%$ and $81.1 \% \pm 14.2 \%$ respectively, $P$ $=0.389$ ) (Figure 1). Drug availability was the only parameter that differed significantly, with a tendency for men to be more satisfied $(P=0.048)$.

\section{Knowledge about TB}

In questions about their knowledge and options of TB, more male patients 'strongly agreed' with the following statements: TB is a dangerous disease if not treated; TB is an infectious disease; recovery from TB is possible; a long treatment duration is very expensive; TB affects work capacity; and it is important to comply with treatment $(P=$ $0.137,0.462,0.272,0.004,0.026$ and 0.997 respectively). However, more females strongly agreed that correct treatment leads to rapid amelioration of symptoms $(P=0.486)$ and they lacked knowledge about TB $(P=0.024)$. Similar proportions of both male and female patients strongly agreed about the importance of continuing treatment even after the disappearance of symptoms $(P=0.561)$. They were also aware of the importance of consulting a physician immediately if new symptoms appear $(P=0.696)$, the importance of being hospitalized $(P=0.679)$, and that malnutrition leads to deterioration of the condition ( $P=0.905)$. Patients' scores on knowledge about TB ranged from $18 \%$ to $80 \%$ with a mean of $64.2 \% \pm$ $9.5 \%$. The mean score of females $(61.9 \%$ $\pm 10.8 \%)$ was significantly lower than males $(65.4 \% \pm 8.6 \%)(t=4.159, P=$ 0.042) (Figure 1).

\section{Perceptions and opinions about social consequences of TB}

Fewer female patients strongly agreed that they feel ashamed about having TB $(P=$ 0.394). Similar proportions of male and female disagreed that the disease affects the way the others deal with them, and they have to hide their disease from their relatives ( $P=0.981$ and 0.915 respectively). Nearly similar proportions of male and fe-

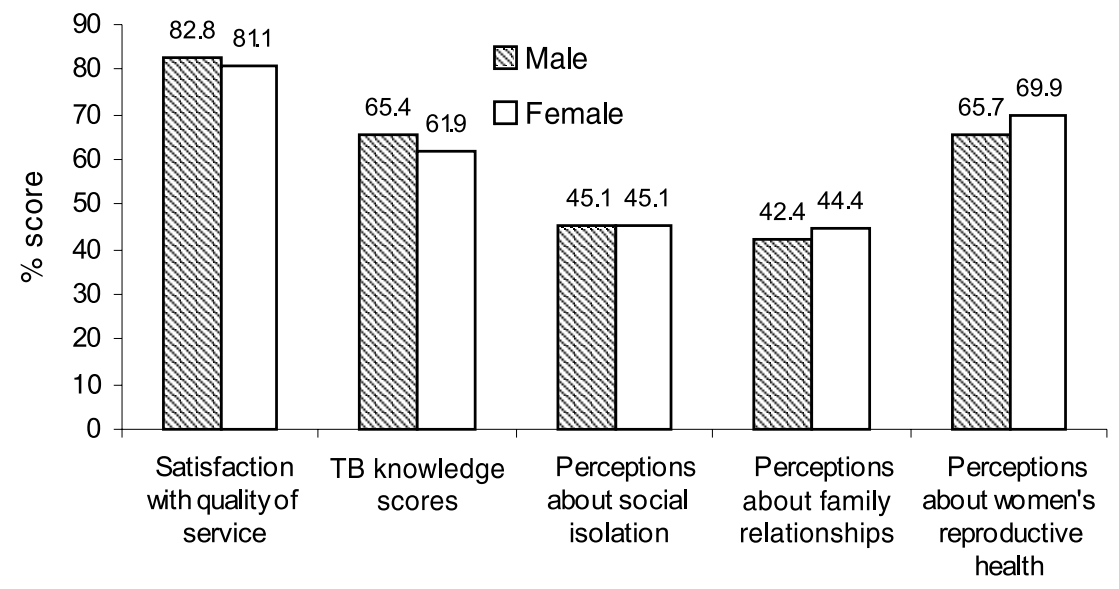

Figure 1 Mean percentage satisfaction scores of tuberculosis patients and knowledge and perceptions about TB

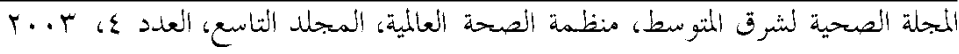


male patients strongly agreed that they prefer to live alone $(P=0.864)$. However, more females strongly agreed that TB affects the relationship with the partner's family $(P=0.509)$. The score of patient's perceptions about the impact of TB on social communication ranged from $4 \%-80 \%$ with a mean score of $45.1 \% \pm 16.0 \%$, similar in females $(45.1 \% \pm 15.9 \%)$ and males $(45.1 \% \pm 16.1 \%)(Z=0.002, P=0.982)$ (Figure 1).

Perceptions and opinions about impact of $T B$ on family relationship

More women did not agree at all that TB affects marital status and familial commitments ( $P=0.044$ and 0.083 respectively). However, more of the males did not agree at all that TB decreases the chance of marriage for young patients $(P=0.009)$ and that the woman has no right to decide about treatment $(P=0.174)$. The score of patient's opinions about the impact on family relationship ranged from $20 \%-80 \%$ with a mean of $43.1 \% \pm 19.4 \%$; there was no significant difference between males $(42.4 \%$ $\pm 18.7 \%)$ and females $(44.4 \% \pm 20.9 \%)(t$ $=0.521, P=0.471)$ (Figure 1$)$.

Perceptions and opinions about impact on women's reproductive health

A significantly higher percentage of females strongly agreed that TB leads to severe complications during pregnancy $(P=$ $0.015)$, TB affects pregnancy $(P=0.026)$ and TB affects breastfeeding $(P=0.008)$. However, no significant gender differences were observed in opinions about the relationship between TB and infertility of woman $(P=0.629)$. Patients' opinion scores on the impact of TB on women and breastfeeding ranged from $18 \%-80 \%$ with a mean of $65.3 \% \pm 22.4 \%$. No statistical significant difference was observed between scores of males $(65.7 \% \pm 22.5 \%)$ and females $(69.9 \% \pm 24.0 \%)(t=1.365$, $P=0.164$ ) (Figure 1).

\section{Patient's compliance}

Figure 2 shows the distribution of TB patients by sex and compliance to health care services in the follow-up period. The mean percentage of non-compliance with drug treatment was $13.5 \% \pm 18.4 \%$ for males and $14.2 \% \pm 19.6 \%$ for females $(P=$ $0.695)$.

The mean percentage of non-compliance to medical examination was $12.4 \% \pm$ $25.2 \%$ for males and $7.9 \% \pm 20.2 \%$ for females $(P=0.120)$. The mean percentage of non-compliance by women $(58.6 \% \pm$ 43.2\%) was significantly higher than that of men $(49.0 \% \pm 44.4 \%)(P=0.049)$.

\section{Outcome at the end of follow-up}

Table 3 shows that only $9.3 \%$ of patients overall remained smear-positive on sputum examination at the end of follow-up; there were significantly more males than females $(10.4 \%$ versus $6.8 \%)(P=0.029)$. Sputum culture was only performed for $29.6 \%$ of TB patients, with no significant differences in results between the sexes $(P=0.641)$. The majority of TB patients (95.2\%) had negative findings on $\mathrm{X}$-ray examination and no significant difference was found between males and females $(P=0.604)$.

Table 4 reveals that $34.1 \%$ of patients completed their treatment, more of the males (34.6\%) than females (33.0\%). Cure was recorded for $60.5 \%$ of patients: $63.1 \%$ of women and $59.4 \%$ of men. Treatment failure was noted in only $4.8 \%$ of patients overall, more males (5.6\%) than females (2.9\%). A minority of patients $(0.6 \%)$ did not complete their treatment. These differences were not statistically significant $(P=$ $0.645)$.

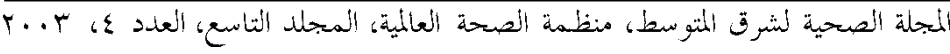




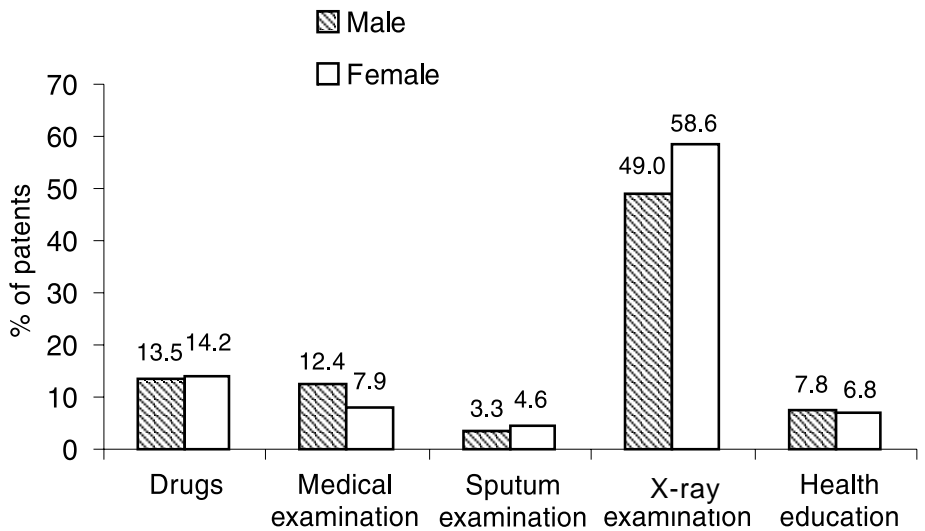

Figure 2 Mean percentage non-compliance for tuberculosis patients (non-compliance defined as performing $80 \%$ or less of required treatment/examinations)

\section{Multivariate analysis of risk factors}

Multiple logistic regression analysis was used to predict risk factors for treatment failure. Due to the large number of factors studied, similar sets of factors were tried each time, namely socioeconomic characteristics and factors affecting utilization patterns. Treatment failure was used as the outcome factor. The forward likelihood ratio model showed that the satisfaction of TB patients with the quality of medical care provided at the chest clinic was the only significant predictor for treatment failure (B = 0.092, Wald $=6.425, P=0.0113, r=$ $0.21, \operatorname{Exp}(\mathrm{B})=1.096)$.

\section{Discussion}

The present study illustrated that male cases of TB outnumbered females by 2.2:1. It is not clear to what extent this difference results from biological factors, sociocultural contexts and from under-recognition of TB among women due to poor access to care [8] or lower reporting of morbidity by women, which may be due to the culture of silence (a tendency to bear pain and suffering silently, or due to constraints of communication). Generally, women in underdeveloped countries face more barriers than men in accessing health care services. However, there is little research to explain the impact of gender inequalities in access to care and on reported sex differences for rates of TB [10].

Borgdorff et al. explored whether lower TB notification rates among women were due to reduced access to health care (particularly diagnostic services for women) [11]. They found that notification rates varied widely among countries, but the female to male ratio was below 1 and decreased with increasing age in almost all. It was < 0.5 in surveys of Southeast Asia and the Western Pacific region and approximately 1 in the African region. This finding suggests that male/female differences in notification

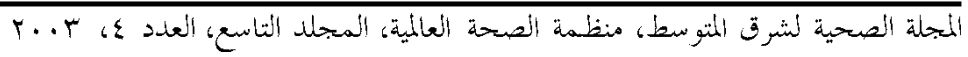




\begin{tabular}{|c|c|c|c|c|c|c|c|c|}
\hline \multicolumn{9}{|c|}{$\begin{array}{l}\text { Table } 3 \text { Distribution of tuberculosis patients by sex and results of investigations at the } \\
\text { end of follow-up }\end{array}$} \\
\hline \multirow{2}{*}{$\begin{array}{l}\text { Results of } \\
\text { investigations }\end{array}$} & \multicolumn{2}{|c|}{ Males $(n=231)$} & \multicolumn{2}{|c|}{ Females $(n=103)$} & \multicolumn{2}{|c|}{ Total $(n=334)$} & \multirow[t]{2}{*}{$\chi^{2}$-test } & \multirow[t]{2}{*}{$P$-value } \\
\hline & No. & $\%$ & No & $\%$ & No & $\%$ & & \\
\hline \multicolumn{9}{|l|}{$\begin{array}{l}\text { Sputum } \\
\text { examination }\end{array}$} \\
\hline Negative & 207 & 89.6 & 96 & 93.2 & 303 & 90.7 & $\chi^{2}=7.459$ & 0.029 \\
\hline Positive & 24 & 10.4 & 7 & 6.8 & 31 & 9.3 & & \\
\hline \multicolumn{9}{|l|}{ Sputum culture } \\
\hline Not done & 164 & 71.0 & 71 & 68.9 & 235 & 70.4 & $\chi^{2}=0.890$ & 0.641 \\
\hline Negative & 54 & 23.4 & 28 & 27.2 & 82 & 24.6 & & \\
\hline Positive & 13 & 5.6 & 4 & 3.9 & 17 & 5.1 & & \\
\hline \multicolumn{9}{|l|}{$X$-ray } \\
\hline Negative & 219 & 94.8 & 99 & 96.1 & 318 & 95.2 & $\chi^{2}=0.269$ & 0.604 \\
\hline Positive & 12 & 5.2 & 4 & 3.9 & 16 & 4.8 & & \\
\hline
\end{tabular}

rates may be largely due to epidemiological differences and not to differential access to health care. In Nepal, however, the male to female sex ratio was 5:1 [12], a difference that can only partly be explained by physiological differences between men and women; other likely factors include geographic, socioeconomic, cultural and health service variables.

Socioeconomic factors play an important role in determining sex differences in TB rates. These factors can influence access to health care [13]. The present research indicated that female patients were

\begin{tabular}{|c|c|c|c|c|c|c|}
\hline \multirow[t]{2}{*}{ Outcome } & \multicolumn{2}{|c|}{$\begin{array}{c}\text { Males } \\
(n=231)\end{array}$} & \multicolumn{2}{|c|}{$\begin{array}{l}\text { Females } \\
(n=103)\end{array}$} & \multicolumn{2}{|c|}{$\begin{array}{c}\text { Total } \\
(n=334)\end{array}$} \\
\hline & No. & $\%$ & No. & $\%$ & No. & $\%$ \\
\hline Treatment completed & 80 & 34.6 & 34 & 33.0 & 114 & 34.1 \\
\hline Cure & 137 & 59.4 & 65 & 63.1 & 202 & 60.5 \\
\hline Treatment failure & 13 & 5.6 & 3 & 2.9 & 16 & 4.8 \\
\hline $\begin{array}{l}\text { Default/treatment not } \\
\text { completed }\end{array}$ & 1 & 0.4 & 1 & 1.0 & 2 & 0.6 \\
\hline Total & 231 & 100.0 & 103 & 100.0 & 334 & 100.0 \\
\hline
\end{tabular}

المجلة الصحية لشرق المتوسط، منظمة الصحة العلمية، المجلد التاسع، العدد ؟، ب... 
more socioeconomically disadvantaged than males. Just less than half of females (46.6\%) were illiterate, the majority of them (93.2\%) were not working and 81.6\% were supported by another family member, either husband or father. Moreover, the mean family size and mean crowding index of female patients were significantly higher than those of males. Hudelson reported similar findings in the UK [5]. He found that socioeconomic factors might be important in different ways. First, they may play a role in determining overall sex differentials in rates of infection and progression to disease; secondly, they may lead to gender differentials in barriers to detection and successful treatment of TB; and thirdly, they may be mediated via denial and concealment of TB diagnosis and disease thus causing delay. Each has an implication for successful TB control programmes.

The pattern of symptoms was different between the sexes. Women tended to present the disease more severely than men. Our study indicated that significantly more women than men presented with purpura. However, symptoms of cough and expectoration were less common among women than among men. This may be associated with increased diagnostic and health care delay. Moreover, poor diagnosis, as indicated by recurrence of the disease and longer duration of hospital admission, was more common among women. Recurrence of the disease was significantly higher among female patients than males (16.5\% compared with $12.1 \%$ ). Hospitalization of TB patients is indicated when treatment of an emergency such as haemoptysis is needed, there are associated conditions such as uncontrolled diabetes, further investigation of suspected TB is needed or the patient is unable to take supervised treatment on an ambulatory basis
[14]. Findings of the present work also revealed that the mean duration of hospital admission was significantly higher for women than for men (75.2 versus 45.6 days).

The study illustrated that more female than male patients had visited private clinics or taken traditional medicines before attending the health facility. Moreover, a significantly higher percentage of females (28.8\%) than males (14.7\%) initially sought treatment from private clinics. In support of these findings, Johansson et al. in Vietnam reported that women had a tendency to seek out private services and practise self-medication before seeking care at public services [14]. Also, Ahmed et al. in Bangladesh reported that women suffering TB relied to a greater extent on home remedies, traditional care and unqualified allopaths than men [15]. Moreover, Liefooghe et al. studied perceptions of TB among patients in Kenya [16]. They found that more women than men considered traditional treatment as a valid alternative to modern treatment.

Promoting adherence by directly observed treatment is much more important than expanding resources on defaulter tracing which is difficult and often unproductive, especially in low income countries [17]. The present study indicated that $15.0 \%$ of TB patients had stopped treatment in the past and that defaulters were more common among males than females. More women than men stopped treatment due to minor side-effects (which are not indications for stopping treatment). However, more men than women had stopped treatment due to the time and money cost. Similar findings were reported by Nair et al. in Bombay who found that more men defaulted in the first month of treatment than women [18]. In fact, the reasons for poor

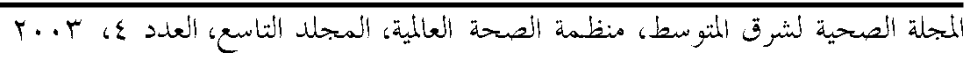


adherence are multifaceted and complex $[19,20]$.

The present study showed that $47.6 \%$ of the sample had been non-compliant with drug treatment in the past, putting them at risk of treatment failure. This figure was higher than that reported by Mousa et al. in Alexandria, Egypt who found that $41 \%$ of smear-positive TB patients were non-compliant [21]. In addition, it was higher than that reported by Gad et al. in Alexandria, Egypt who found that about one-third of the patients were non-compliant [22]. In New Delhi, $26.9 \%$ of patients failed to complete their TB regimen within 9 months [23].

The present study illustrated a lower non-compliance with health education and medical examination in the past among female patients compared with males, although this difference is not statistically significant. This finding is consistent with that reported by Yanai et al. in Sweden who showed that women are generally more likely to comply with medical care than men [24].

Patients may default on treatment because of the inconvenience of frequently reporting to clinics with inconvenient opening hours situated far from their homes $[10,25,26]$. The present work indicated that TB patients were largely satisfied with the quality of services provided (mean score $82.5 \%$ ). Overall, no significant sex difference was observed in patients' satisfaction with the quality of services provided.

The present study found that TB patients had limited understanding and knowledge about TB, with a mean knowledge score of only $64.2 \%$. Knowledge was significantly worse among women than men. Liam et al. in Malaysia [27] reported the same finding. Poor compliance was encountered among Malaysian patients who had misconceptions and limited knowledge about the disease and its treatment. Studies in Vietnam and Malawi $[28,29]$ explored gender differentials in knowledge, beliefs and attitudes towards TB and its treatment and how these factors can influence patients' compliance with treatment. They reported that insufficient knowledge and the cost of treatment were the main obstacles to compliance among men, while sensitivity to interactions with health staff and the stigma of disease were reported as the main obstacles among women.

Patients believed that TB affects marital relationships and diminishes marriage prospects for young TB patients. They also believed that TB affect women's reproductive health. These perceptions were significantly more common among female than male patients. Liefooghe et al. in Pakistan reported similar findings [30]. They found that TB patients perceived the disease to have many consequences on them and their families, that TB in one partner may lead to divorce and that female patients are more affected by the social consequences of TB.

The present study revealed a gender disparity in sputum results of TB patients. Significantly fewer females (6.8\%) showed a sputum-positive test at the end of the follow-up compared with males $(10.4 \%)$. The possible reasons for low sputum positivity among women may range from poor explanation of sputum production techniques, more women having paucibacillary disease and non-productive cough, cultural inhibitions against forcing up expectoration or genuine inability to produce good quality sputum leading to submission of saliva [8]. Consistent with this finding, Boeree et al. in Malawi [29] and Reider et al. [31] in the USA reported that significantly fewer women submit sputum samples and are diagnosed with smear-positive TB.

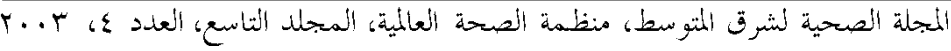


Treatment failure was recorded among $4.8 \%$ of TB patients, and although more males than females failed (5.6\% compared with $2.9 \%$ ), this difference was not statistically significant. Our failure rate was slightly higher than those reported before in Egypt (3.2\% and 2.2\%) [32]. Becerra et al. indicated that treatment failure of DOTS is strongly predictive of active pulmonary multi-drug resistant TB [33]. The mixing of different drug regimens will tend to increase the failure rate and probability of secondary resistance [34]. Fully supervised or directly observed intermittent treatment regimens have been reported to be highly successful in achieving adequate adherence to the intensive DOTS chemotherapy and in attaining the very high completion rate of the full course [35].

Multivariate logistic regression analysis revealed that patients' satisfaction with the quality of care provided was the only predictor of treatment outcome among TB patients. This indicates that good quality services were significantly associated with better treatment outcome.

\section{Conclusions}

We conclude that effective supervision of a national TB programme should ensure availability of equipment as well as qualifications of the caregivers by training to improve their skills and performance. This will lead to increased satisfaction and higher attendance rate by patients, and consequently a better outcome of treatment.

\section{Acknowledgement}

This investigation received technical and financial support from the joint WHO Eastern Mediterranean Region (EMRO), Division of Communicable Diseases (DCD) and the WHO Special Programme for Research and Training in Tropical Diseases (TDR): the EMRO/DCD/TDR Small Grants Scheme for Operational Research in Tropical and Communicable Diseases.

\section{References}

1. TB: a global emergency. WHO report on the TB epidemic. Geneva, World Health Organization, 1994 (WHO/TB/94.177).

2. Treatment of tuberculosis: guidelines for national programmes, 2nd ed. Geneva, World Health Organization, 1997 (WHO/ TB/97.220).

3. Howson CP et al. In her lifetime: female morbidity and mortality in sub-Saharan Africa. Washington DC, National Academy Press, 1996.

4. Connolly M, Nunn P. Women and tuberculosis. World Health Statistics Quarterly, 1996, 49:115-9.

5. Hudelson P. Gender differentials in tuberculosis: the role of socio-economic and cultural factors. Tubercle and lung disease, 1996, 77:391-400.

6. Holmes CB, Hausler H, Nunn P. A review of sex differences in the epidemiology of tuberculosis. International journal of tuberculosis and lung disease, 1998, 2(2): 96-104.

7. National Tuberculosis Control Programme. DOTS: a new strategy for tuberculosis control. Cairo, Egypt, Ministry of Health and Population. http://www.emro. who.int/stb/egypt/DotsNewStrategy.htm (last accessed 12/05/04).

8. Manderson L, Mark T, Woelz N. Women's participation in health and development

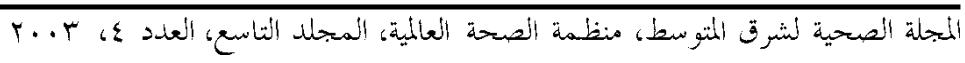


projects. Geneva, World Health Organization, 1996 (WHO/TDR/GTD/RP/96.1).

9. Gender and tuberculosis: towards a strategy for research and action. Geneva, World Health Organization, 1999 (WHO/CDS/TB/2000.280).

10. Uplekar MW et al. Attention to gender issues in tuberculosis control. International journal of tuberculosis and lung disease, 2001, 5(3):220-4.

11. Borgdorff MW et al. Gender and tuberculosis: a comparison of prevalence survey with notification data to explore sex differences in case detection. International journal of tuberculosis and lung disease, 2000, 4(2):123-32.

12. Stebbiuy M. Gender and TB. Perspectives from Nepal. Alice Springs, Australia, Territory Health Services, 2001.

13. Grange J, Story A, Zumla A. Tuberculosis in disadvantaged groups. Current opinion in pulmonary medicine, 2001, 7(3): 160-4.

14. Johansson E et al. Gender and tuberculosis control. Perspective on health seeking behaviour among men and women in Vietnam. Health policy, 2000, 52(1): 33-51.

15. Ahmed SM et al. Gender. Socioeconomic development and health seeking behavior in Bangladesh. Social science and medicine, 2000, 51(3):361-71.

16. Liefooghe $\mathrm{R}$ et al. From their own perspective. A Kenyan community's perception of tuberculosis. Tropical medicine and international health, 1997, 2(8): 809-21.

17. Maher D et al. Treatment of tuberculosis: guidelines for national programmes, 2nd ed. Geneva, World Health Organization, 1997.

18. Nair DM, George A, Chacko KT. Tuberculosis in Bombay: new insights from poor urban patients. Health policy and planning, 1997, 12(1):77-85.

19. Sumartojo E. When tuberculosis treatment fails. A social behavioural account of patient adherence. American review of respiratory disease, 1993, 147(5): 1311-20.

20. Goncalves $\mathrm{H}$ et al. Tuberculosis treatment adherence in Pelotas, Brazil, from the patient's perspective [in Portuguese]. Cadernos de saude publica, 1999, 15(4):777-87.

21. Mousa I et al. Smear positive pulmonary tuberculosis. Preliminary results of a study in Alexandria and Menoufia, Egypt. Eastern Mediterranean health journal, 1993, 1(3):166-52.

22. Gad A et al. Compliance with antiTB drugs among tuberculosis patients in Alexandria, Egypt. Eastern Mediterranean health journal, 1997, 3(2):244-9.

23. Household survey of medical care. New Delhi, NCAER (National Council of Applied Research), 1992.

24. Yanai N, Punagrassami P, Yanai H. Compliance to tuberculosis treatment: a gender perspective. In: Diwan VK, Thorson A, Winkvist A, eds. Gender in tuberculosis: an international research workshop, May 24-26, 1998. Gotenberg, Sweden, Nordic School of Public Health, 1998.

25. Health, households and women, lives: a study of illness and child bearing among women in Nasik District, Maharashtra. Mumbai, CEHAT (Research Centre of Anusandhan Trust), 1999.

26. Fine PEM. Immunities in and to tuberculosis: implications for pathogenesis and vaccination. In: Porter JDH, MC Adam KPWJ, eds. TB: back to the future. Chichester, Wiley, 1994.

27. Liam CK et al. Attitudes and knowledge of newly diagnosed tuberculosis pa-

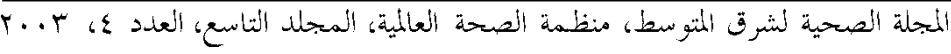


tients regarding the disease and factors affection treatment compliance. International journal of tuberculosis and lung disease, 1999, 3(4):300-9.

28. Johansson E et al. Attitudes to compliance with tuberculosis treatment among women and men in Vietnam. International journal of tuberculosis and lung disease, 1999, 3(1):862-8.

29. Boeree MJ et al. Gender differences in relation to sputum submission and smear positive pulmonary tuberculosis in Malawi. International journal of tuberculosis and lung disease, 2000, 4(9): 882-4.

30. Liefooghe $R$ et al. Perception and social consequences of tuberculosis: a focus group study of tuberculosis patients in Sialkot, Pakistan. Social science and medicine, 1995, 41:1685-92.

31. Rieder $\mathrm{HL}$ et al. Evaluation of $\mathrm{a}$ standardised recording tool for sputum smear microscopy for acid-fast bacilli under routine conditions in low income countries. International journal of tuber- culosis and lung disease, 1997, 1(4): 339-45.

32. Kamel NM, Darwish IA, Tayel SE. The epidemiologic features of tuberculosis and impact of tuberculosis control programme in Alexandria. Bulletin of the High Institute of Public Health, 2001, 31(4):1-24.

33. Becerra MC et al. Using treatment failure under effective directly observed shortcourse-chemotherapy program to identify patients with multidrug-resistant tuberculosis. International journal of tuberculosis and lung disease, 2000, 4(2): 108-14.

34. Murray C, Styblo K, Rouillou A. Tuberculosis. In: Jamison DT, Mosley WH, Measham AR, eds. Disease control priorities in developing countries. Washington DC, World Bank Publications, 1993:236.

35. Croften J, Horne N, Miller F. Clinical tuberculosis, 1st ed. London, MacMillian, 1999. 